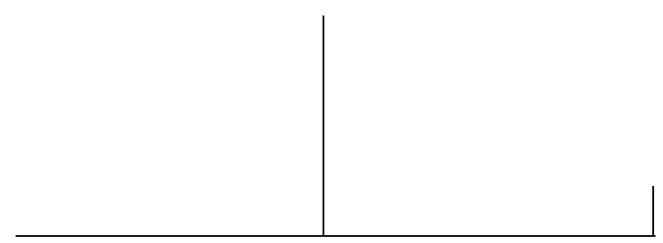

Rev. Latinoam. Psicopat. Fund., São Paulo, 16(3), 373-386, set. 2013

\title{
"Graças a Deus vomito, senão morria": o sintoma bulímico e a clínica psicanalítica em um hospital público
}

\author{
Marcus Vinícius Rezende Fagundes Netto*1 \\ Niraldo de Oliveira Santos*2 \\ Glaucia Rosana Guerra Benute*3 \\ Mara Cristina Souza de Lucia*4
}

\begin{abstract}
Os manuais de classificação e diagnóstico são bastante objetivos ao descreverem a etiologia, o diagnóstico diferencial e o tratamento para todos aqueles que padecem dos chamados transtornos alimentares. Todavia, se a Medicina, como área do saber científico, deve generalizar, a psicanálise tem como campo de pesquisa o inconsciente, o sujeito como efeito de linguagem. Com isso, a partir de observações sobre as entrevistas preliminares de um caso, no qual se evidenciava o sintoma bulímico, o presente artigo coloca em relevo algumas questões: as especificidades do sintoma para a psicanálise, a diferença radical entre instinto e pulsão e a particularidade da produção de saber em psicanálise.
\end{abstract}

Palavras-chave: Psicanálise, medicina, sintoma, bulimia

*1 Universidade Brás Cubas (Mogi das Cruzes, SP, Brasil).

*22Hospital das Clínicas da Faculdade de Medicina da Universidade de São Paulo (São Paulo, SP, Brasil).

${ }^{* 3}$ Hospital das Clínicas da Faculdade de Medicina da Universidade de São Paulo (São Paulo, SP, Brasil).

*4Hospital das Clínicas da Faculdade de Medicina da Universidade de São Paulo (São Paulo, SP, Brasil). 


\section{Do universal para o particular e retorno}

Os manuais de classificação e diagnóstico como o DSM-IV (2002) e a CID-10 (2011) são bastante objetivos ao descreverem o que é conhecido na literatura especializada como transtornos alimentares. Assim, os critérios diagnósticos para bulimia nervosa (BN), um desses transtornos que aflige, em sua maioria, mulheres jovens, compreendem: a) preocupação desproporcional com a forma e peso do corpo; b) grande sentimento de culpa e de descontrole, após ingestão, em curto espaço de tempo, de uma grande quantidade de alimento; c) engajamento em comportamentos compensatórios, objetivando perda e/ou controle do peso que vão desde dietas rigorosas até à autoindução de vômito.

Ainda segundo o DSM-IV (2002), a etiologia da BN seria multifatorial e englobaria causas genéticas, sociais e psicológicas. Com relação ao diagnóstico diferencial, dever-se-ia excluir outros quadros que podem apresentar sintomatologia semelhante, como tumores cerebrais, transtornos gastrointestinais e outras doenças psiquiátricas como o transtorno da depressão maior e a própria anorexia nervosa. Finalmente, naquilo que concerne o tratamento desses pacientes, há consenso de que o mesmo deva ser multidisciplinar, envolvendo profissionais da psiquiatria, da psicologia e da nutrição.

Epidemiologia, etiologia, critérios diagnósticos, diagnóstico diferencial, tratamento ... A sensação de tranquilidade diante da ilusão de tudo já ter sido dito, descrito e explicado é inevitável. Então poderíamos nos perguntar: e a psicanálise, o que teria ela a dizer sobre a bulimia?

Ora, sabemos que o sujeito da psicanálise, sujeito do inconsciente, é um efeito de linguagem e, como tal, surpreende-se quan- 


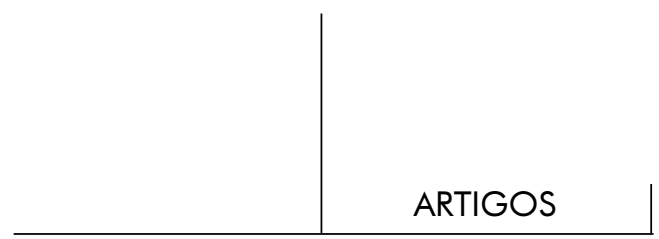

do o que diz aponta para sua divisão, mas surpreende também aquele que o escuta: "Graças a Deus vomito, senão morria!". Isso é o que afirma Maria, paciente diagnosticada como bulímica e atendida em um hospital universitário. Ou seja, apesar de todo o esforço da psiquiatria biológica de categorizar e americanizar o sofrimento humano (Walters, 2010), essa paciente, em tom denunciatório, enaltece seu modo de gozo, e um sintoma que, pela lógica do discurso médico, deveria ser causa de grande sofrimento e, por isso, sanado.

Com isso, quando tudo aparentemente já foi falado acerca da bulimia nervosa, o sujeito do inconsciente insiste bravamente e pede a palavra. Portanto, seguindo a recomendação de Freud (1912/1996) de que, em psicanálise, clínica e pesquisa coincidem, pretendemos aqui, por meio de observações sobre um caso, trazer contribuições para a clínica dos sujeitos que sofrem de bulimia. Afinal, não nos esqueçamos de que Freud descrevia o caso único (Dora, Homem dos ratos, Homem dos Lobos...) esperando que dele jorrasse universal.

\section{Observações a partir das entrevistas preliminares de um caso}

Maria tem 23 anos, mora em São Paulo há algum tempo, mas sua família é de uma cidade pequena do estado do Rio de Janeiro. Atualmente, trabalha como vendedora em um pequeno mercado de seu bairro e foi encaminhada por um médico de um posto de saúde da sua região com suspeita de bulimia nervosa. Todavia, Maria dizia não se achar doente, vomitava apenas para evitar o ganho de peso e só resolvera procurar atendimento psicológico por muita insistência da família e do próprio médico.

No início do tratamento, sempre chegava encapuzada, sentava-se de lado na cadeira, pouco falava e não se importava de ficar quase toda a sessão em silêncio, o que, por sua vez, dificultava a entrada da paciente no dispositivo analítico.

Assim, a proposta do presente artigo é fazer algumas considerações sobre as entrevistas preliminares de um caso. Falando de outra forma, tenciona-se aqui colocar em relevo a importância da dimensão da escuta para o estabelecimento da transferência, a possibilidade de uma aposta diagnóstica (Freud, 1913/1996) e a formação de um sintoma analítico que, por sua vez, devem anteceder o início de uma análise propriamente dita (Quinet, 2007).

Atrelado a isso, partindo do adágio lacaniano de que o inconsciente é estruturado como uma linguagem, trazemos algumas falas da paciente que denunciam seu posicionamento diante do Outro e que nos dão pistas para a direção do tratamento. Todavia, é necessário ressaltar que não nos propomos aqui a uma leitura pela via do fenômeno, no sentido de que "se disse isso, logo...". Caso o 
fizéssemos, estaríamos reproduzindo, mesmo que de maneira diversa, o que ocorre nos manuais diagnósticos. O que se pretende sublinhar neste estudo é a soberania da clínica. Por isso, cada caso deve ser escutado em sua singularidade, levando em consideração os significantes mestres produzidos e a maneira pela qual eles se articulam na história libidinal do sujeito. ${ }^{1}$

Voltemos então ao caso de Maria.

- "Do nada, abri a geladeira e comi tudo. Não parei enquanto não tinha mais nada. Depois vomitei tudo".

Ao receber para tratamento um paciente com o dito sintoma bulímico, o que de imediato salta aos olhos é a distância que se estabelece entre os seres falantes e os seres naturais, guiados por seus instintos. Ou seja, para nós, seres alienados na linguagem, marcados pelo significante, não há instinto. Com isso, a proposição matemática a = a não é verdadeira, já que nem sempre se come qualquer coisa quando se está com fome e nem sempre se para de comer quando o estômago está cheio.

Freud (1915a/1996), atento a essa pura diferença, elaborou o conceito de pulsão que, segundo ele, estaria entre o psíquico e o somático, teria uma força constante e seus objetos poderiam ser os mais variáveis. Assim, diferentemente do instinto, a pulsão não pode se satisfazer por completo, "não tem dia nem noite, não tem primavera nem outono" e nem possui um objeto exclusivo para sua satisfação (Lacan, 1964/2008, p. 163).

A partir disso, o que chama atenção em alguns pacientes que sofrem com a bulimia, é a ligação feita entre o ato de comer e um objeto bastante particular, que não coincide com a comida, apesar de se fazer presente por intermédio dela ou pela sua ausência - o tudo/nada.

Pela fala de Maria, não podemos deixar de notar que esse "tudo" comer vem acompanhado em seu discurso de um "nada" reter. "Tudo" e "nada", portanto, são escutados desde a primeira sessão não só como significantes presentes no discurso de Maria, mas também como objetos eleitos pela paciente para intermediar sua relação com o Outro. A partir disso, questionamentos podem ser feitos: Que "nada" era esse que fazia Maria abrir a geladeira e comer "tudo"? Vomitar "tudo"? "Tudo" o quê? A comida? Essas eram perguntas que permearam os

${ }^{1}$ Não ignoramos, obviamente, as peculiaridades do atendimento de um paciente em um serviço público de saúde. Todavia, as possibilidades e limites de se levar a escuta analítica para uma instituição como um hospital-escola merecem, devido a sua complexidade, serem estudados em um outro momento.

Rev. Latinoam. Psicopat. Fund., São Paulo, 16(3), 373-386, set. 2013 
primeiros atendimentos até o dia em que Maria conta sobre sua relação com a irmã mais velha, com quem morou logo depois de chegar a São Paulo.

- "O problema não é ela, é ela toda."

Essa é a fala que melhor sintetiza a maneira como Maria se colocava diante da irmã que, de fato, para a paciente era toda. Ou seja, a ela não faltava nada, o que, para Maria, era insuportável. Afinal, sabemos que o sujeito usa a falta do Outro como bússola de seu desejo. Isso se dá no Édipo. Assim, é preciso um olhar da mãe em outra direção para que a criança perceba que ela não satisfaz o Outro materno totalmente, que há algo para além do infans que aponta para a falta materna. É por isso que tentamos a todo custo - custo da neurose - responder ao enigma: "O que o outro quer de mim?". Não é por acaso que Lacan (19691970) nos lembra que o desejo do sujeito é o desejo do desejo do Outro.

$\mathrm{Na}$ bulimia, em específico nos casos de neurose, parece que o sintoma de comer tudo e nada reter tem uma função - função de inflingir uma falta no Outro materno para que o desejo se instaure. O fenômeno bulímico, dessa forma, é uma estratégia para assegurar o desejo (Recalcati, 2001).

No caso aqui relatado, a irmã de Maria parece esse lugar. Maria era "obediente". Aliás, bastava a irmã lembrar-se que Maria ainda não havia vomitado, para que essa atendesse prontamente a seu pedido/imperativo. O vômito entrava, paradoxalmente, como um objeto que satisfazia a irmã, mas que também apontava sua falta. "Ela não sabe o que fazer" - diz Maria, mostrando como seu sintoma serve de enigma e tem uma dimensão de endereçamento. Portanto, Maria parece se colocar no campo da neurose, onde o sintoma é o que retorna no simbólico, a partir de um tipo específico de negação - o recalque.

Além disso, Lacan (1964/2008), no Seminário 11, fala sobre o processo lógico de causação do sujeito, que depende de duas operações - alienação e separação. É importante enfatizar, todavia, que não há ideal. Não se trata de se separar totalmente para se tornar sujeito. Não há um sem o Outro. A alienação é uma condição do sujeito, está posta. Estamos alienados na linguagem, submetidos aos efeitos do significante. Um significante representa um sujeito para outro significante. Não há, com isso, a possibilidade de um único significante definir o sujeito que, por sua vez, é dividido pela linguagem.

Seguindo essa mesma trilha, a alienação total também é mortífera. É preciso um certo grau de separação, um espaço. "O problema não é ela, é ela toda" retomamos a fala de Maria para que fique claro que "o não se nutrir ou o se encher de nada" não é tão absurdo, não é tão egodistônico. A bulimia parece ser então uma tentativa de pseudosseparação com relação ao Outro materno que, neste caso, é encarnado na figura da irmã mais velha (Silva; Bastos, 2006). 
Não é a toa que Maria diz não estar doente: "Graças a Deus vomito, senão morria". Aqui o sujeito do inconsciente entra em cena para colocar um saber não sabido no lugar da verdade e nos mostrar que o sintoma bulímico é uma primeira tentativa de tratamento. Algo que, mesmo de forma capenga, serve de escudo para o desejo, para a vida. Falando de outro modo, é "o sintoma como solução inventada pelo sujeito para alojar sua singularidade no comum" (Sauret, 2006, p. 28).

- "Aconteceu há muito tempo. Lembro e fico triste, mas não consigo falar."

É em uma sessão aparentemente sem muitas novidades que Maria passa a jogar na transferência com seu "ágalma histérico" (Gorostiza, 2011), mas não sem fazer, ao mesmo tempo, movimentos de que vomitaria - literalmente - na presença do analista.

Diante desse endereçamento, é dito à Maria: “Vá, mas volte!”. Essa intervenção, que mais tarde se revelaria como sendo um ato, propicia que o sujeito entre em cena, interrogue-se sobre seu sintoma e diga que vomitou porque estava triste. $\mathrm{O}$ ato analítico então engendra uma descolagem pulsional em seu cogito particular (Vomito, logo sou.) e, ao mesmo tempo, circunscreve a diferença radical entre o saber universal dos manuais diagnósticos (Vomito porque me acho gorda.) e o saber singular construído em análise (Vomito quando estou triste.).

Com isso, é nesse ponto de dialetização em que o vômito não é mais visto por Maria de forma imaginária, como algo que é feito para não se engordar. Aqui o sintoma toma uma outra dimensão - a dimensão de metáfora.

Freud (1893-1895/1996) nos diz que a histérica sofre de reminiscências. Além disso, também diferencia a neurose obsessiva da histérica dizendo que enquanto aquela caracteriza-se, dentre outras coisas, por um deslocamento do afeto e pelo investimento do pensamento, na neurose histérica o afeto investe o corpo (Freud, 1915b/1996).

Logicamente, esses fenômenos não são o suficiente para algo conclusivo com relação ao diagnóstico estrutural. Os fenômenos, como observa Lacan (1955-1956), podem ser enganosos. A aposta diagnóstica só deve ser feita com base na transferência, na realidade inconsciente colocada em ato ou, nas palavras de Lacan (1964/2008, p. 171), na "atualização da realidade inconsciente". É disso que trataremos a seguir.

-"Eu não ia vir mais, mas sonhei e vim. Era uma mulher que sabia das minhas coisas. Para ela eu podia contar."

Maria chega a uma das sessões intrigada com um sonho que a fez decidir continuar a análise. Fala que sonhara com uma mulher bonita, que sabia das coisas e que atendia no mesmo consultório do analista. "Não era você!" - complementa. 


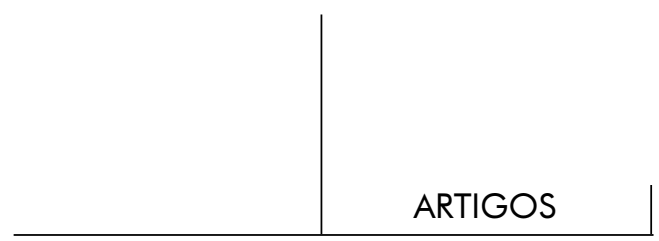

Freud (1925/1996) nos alerta para ficarmos atentos às denegações. "Quem disse que era eu?" - o analista pergunta. Maria ri, mas não sem continuar a reinar sobre o mestre - sujeito suposto saber - que ela mesma elegeu na transferência: "Você não sabe de nada. Ninguém sabe. Só eu." Ou seja, uma bela manobra histérica que começa a marcar presença não só com o analista mas também com a irmã, a quem sempre obedeceu.

-"Esperei o Lulu furar a roupa dela. Só tirei depois..."

A irmã de Maria comprara um cachorro para seu filho, mas Maria o tomou como seu. Isso foi importante. Lulu iniciou uma série de terceiros que começou a tornar possível uma separação entre Maria e sua irmã. Maria conta que certo dia Lulu pegou uma blusa da irmã para brincar. Segundo ela, esperou até que a roupa se rasgasse para então tirar a peça da boca do cachorro. "Por que acha que fez isso?" - o analista pergunta. "Tenho raiva dela." Maria parecia começar a conseguir expressar seus afetos que não pela via do vômito, e isso é marcado na sessão. Maria então diz que a irmã não queria mais deixá-la vir à análise. Quando indagada do que achava da decisão da irmã, Maria diz que iria mentir, mas que continuaria vindo. "É melhor que ficar em casa", complementa. Em um primeiro momento, poder-se-ia questionar o valor que Maria dava a sua análise. Todavia, Lulu e, neste momento, a mentira para continuar a análise pareciam desempenhar um importante papel para que um novo posicionamento diante da irmã começasse a se engendrar e isso deveria ser escutado e acolhido. Nas sessões seguintes, Maria começa a falar de um irmão que entrará nesta mesma série.

•"Ele é chato, mas é legal."

Nas semanas que se passaram, Maria decidira sair da casa da irmã e ir morar com o irmão. Essa separação física foi fundamental e fez com que Maria começasse a se colocar de maneira diferente com relação à irmã. "Ela fala e eu finjo que escuto" - diz que agora só se encontrava com a irmã quando queria. Aqui, no entanto, uma ressalva deve ser feita. Não se deve deixar de levar em consideração a dimensão de gozo instaurada na relação entre Maria e a irmã. Com isso, a decisão de sair da casa da irmã foi escutada, mas não sugerida. O espaço físico entre ela e a irmã só foi possível porque outro espaço já vinha sendo construído, a partir de "terceiros" (Lulu, mentira, analista) que começaram a se fazer presentes nas sessões e marcados pelo analista.

Quanto ao irmão, esse aparece no discurso de Maria como aquele que é chato, mas é legal. Há um espaço. Espaço para negociação de tarefas domésticas e obrigações financeiras em casa, mas também a transgressão. Maria começa a andar com meninas que são "má influência" e que lhe apresentam "um comprimido branco, calmante". O analista, neste ponto, preocupa-se e quase questiona 
o uso do medicamento. Mas o uso da droga entra na dinâmica grupal como possibilidade de fazer laço, de causação de desejo. "Se eu não usar, como vai ser?" - Maria se pergunta referindo-se à necessidade de fazer parte do grupo. A partir disso, é possível a Maria tentar tatear o desejo do Outro de outras formas, que não apenas pelo sintoma bulímico.

Aliás, nas semanas seguintes, outro significante - "decidir" - começa a permear as sessões. Decide fazer um curso profissionalizante sendo alvo de orgulho do irmão e desiste; decide parar de vomitar para agradar um amigo, sustenta isso por uma semana, mas desiste; decide que vai se matar dali a um mês, conta para suas colegas de trabalho e desiste. Ou seja, diante de tantas "decisões e desistências" que envolvem o Outro - alienação no campo do Outro -, Maria sustenta a insatisfação do desejo como forma de se separar, de se aproximar e se afastar, ou melhor, de sustentar o desejo, que antes tinha o vômito como escudo.

Neste momento, Maria não vomitava há duas semanas e já havia se convencido de que estava doente e iria ao médico. "Só vomito quando o médico me dá um remédio que não quero tomar." - diz Maria, mostrando que o mestre de fato não tem vez. Quanto ao analista, resta-lhe continuar escutando suas "decisões".

•"Decidi que vou parar de vir. Já melhorei. Só vomitei duas vezes..."

"Por que você acha que vomitou?" - convoca o analista. "Já percebi que vomito quando estou triste." O analista então diz que Maria poderia parar a análise, essa era uma decisão dela. Uma escolha. Acrescenta que, no entanto, havia questões importantes que ainda deveriam ser trabalhadas como o porquê de vomitar quando se está triste. "Se eu estiver aqui, eu volto." Maria então diz que pretendia voltar para a casa de seus pais. "Sei que se eu voltar..." - Maria interrompe a própria fala e fica em silêncio. O analista também faz silêncio. Maria fala que não importa o lugar, pois, onde estiver, vai lembrar, ficar triste e vomitar. Diz ainda que agora que está tomando remédio (antidepressivo) está mais boba do que já era. O significante "boba" já havia aparecido em algumas sessões sempre ligado à fala da irmã, que a julgava dessa forma. O analista então intervém: "Será que você é boba mesmo?" O analista então diz que não achava Maria boba. Afinal, se fosse boba, não conseguiria perceber que vomita não por medo de engordar, mas devido a uma tristeza. Se fosse boba, não continuaria a análise sem sua irmã saber e nem iria morar com o irmão, o que para ela foi tão importante. Além disso, uma pessoa boba não saberia que voltar para a casa dos pais poderia não ser uma boa decisão... O analista aqui é interrompido por uma risada. "É verdade, não sou boba." O analista encerra a sessão dizendo que a esperaria na semana seguinte. "Até semana que vem", diz Maria. 


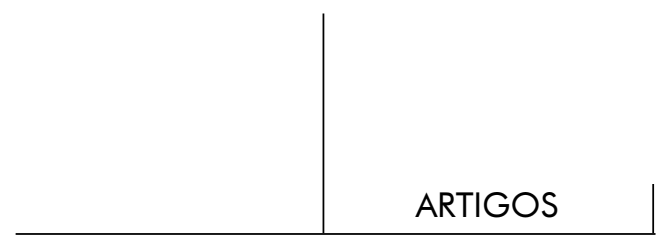

Do particular para o universal e a invenção no caso a caso

Antes de concluirmos, alguns apontamentos são ainda necessários. Em um hospital-escola, o analista é convocado a atuar não só na clínica, mas também no ensino e na pesquisa que, no discurso universitário, muitas vezes, são contemplados de forma separada. Assim, o presente trabalho, ao atrelar clínica e pesquisa, não só problematiza tal separação, como traz para primeiro plano a importância da escuta e do caso único, apostando, com isso, que algo da dimensão do sujeito possa ser transmitido.

Portanto, a partir das considerações aqui tecidas, pergunta-se: O que no caso de Maria repete-se em outros casos? O que da condução deste caso pode fazer eco na escuta de outros pacientes? O que do particular tange o universal?

Primeiramente, o que nos chama atenção é o fato de que pacientes com esse tipo de construção sintomática, muitas vezes, recusam-se a falar, a "colocar para fora”. Mas não nos deixemos enganar. A expressão está em cena, mesmo que o corpo seja seu palco! A angústia, pela falta da palavra, está em seu estado máximo e, como nunca, sentida no corpo, no eu como projeção de superfície (Freud, 1925/1996).

Ou seja, em casos como esse, é necessário que façamos uma precisa diferença: sintomatizar a angústia, colocar a angústia em ato no corpo é diferente de se ter no corpo um sintoma a ser decifrado. O sintoma mente, a angústia nunca! Por isso, muitas vezes, a decifração do sintoma tem de ceder lugar, pelo menos temporariamente, à sintomatização da angústia, à condução do paciente à consistência de uma sintomatização máxima (Laurent, 2005). No caso aqui relatado isso se dá quando Maria sai da sessão para vomitar e volta falando do seu sintoma não mais como angústia encarnada, mas como aquilo que pede decifração.

Percebe-se, com isso, uma passagem do humor melancólico ligado ao gozo masoquista superegoico da devastação feminina ligada ao Outro materno, para a impulsão sádica da demanda de amor. A obediência de vomitar diante do imperativo veiculado pela pergunta da irmã "Não vai vomitar hoje?” dá lugar, portanto, a uma demanda de amor dirigida ao analista pela ameaça de interromper os atendimentos. Como enfatiza Guimarães (2012):

Essas estratégias, na transferência, aliadas às táticas utilizadas pelo analista, resultam muito habitualmente numa fixação na transferência que põe a nu uma base histérica desestabilizada, que estava refreada, amortecida, até mesmo esmagada sob fatores de defesas obsessivas,(...) Quando este núcleo histérico desestabilizado emerge em ato nas demandas dirigidas ao analista, digo a mim mesma, nesses momentos de minha prática analítica: Bem-vinda transferência! (p. 285)

Rev. Latinoam. Psicopat. Fund., São Paulo, $16(3)$, 373-386, set. 2013 
Em consequência, o tratamento do sintoma bulímico - não que se trate só disso - encontra-se para além da informação psicoeducativa ou da prescrição nutricional. Por isso, a escuta não pode se enveredar por caminhos já trilhados e cheios de sentido. $\mathrm{O}$ analista nada sabe sobre o paciente, além daquilo que lhe é dito na cadeia significante. Isso, deve(-se) saber! Em outras palavras, a porta da compreensão (eu-oica) deve ser fechada, caso se tencione abrir a porta da compreensão analítica (Lacan, 1953-1954/2009).

Logicamente, não fazemos aqui apologia a um descompromisso com a teoria. Se assim o fosse, não haveria razão para este trabalho. Ao analista é preciso saber para não saber. Sua formação, portanto, deve ser sólida - estudo teórico, análise e supervisão. Só assim lhe é possível bancar este lugar de ignorância ignorância-douta (Jorge, 2006). “Análise é cara!" - é o que dizem. Afirmação verdadeira, pois, apropriando-se de sua história, o paciente paga ao abrir mão de uma cifra de gozo - modo paradoxal de satisfação que também envolve sofrimento.

Todavia, para que isso se dê, o analista não deve ter horror a seu ato. Pelo contrário! Se, por um lado, como nos alerta Lacan (1969-1970/2008), temos os especialistas da medicina operando, cada vez mais, pela lógica da resposta direta à demanda, os analistas, por sua vez, deparam-se a todo tempo com o fato clínico que tem, na singularidade do caso a caso e na transferência, sua potência criativa.

\section{Referências}

American Psychiatric Association. (2002). Manual diagnóstico e estatístico de transtornos mentais (DSM-IV). Porto Alegre: Artmed.

Freud, S. (1996). Estudos sobre a histeria. In Edição Standard Brasileira das Obras Psicológicas Completas de Sigmund Freud. v. II. Rio de Janeiro: Imago. (Trabalho original publicado em 1893-1895).

Freud, S. (1996). Recomendações aos médicos que exercem a psicanálise. In Edição Standard Brasileira das Obras Psicológicas Completas de Sigmund Freud. v. XII. Rio de Janeiro: Imago. (Trabalho original publicado em 1912).

Freud, S. (1996). Sobre o início do tratamento. In Edição Standard Brasileira das Obras Psicológicas Completas de Sigmund Freud. v. XII. Rio de Janeiro: Imago. (Trabalho original publicado em 1913).

Freud, S. (1996). O instinto e suas vicissitudes. In Edição Standard Brasileira das Obras Psicológicas Completas de Sigmund Freud. v. XIV. Rio de Janeiro: Imago. (Trabalho original publicado em 1915a).

Freud, S. (1996). A repressão. In Edição Standard Brasileira das Obras Psicológicas 
Completas de Sigmund Freud. v. XIV. Rio de Janeiro: Imago. (Trabalho original publicado em 1915b).

Freud, S. (1996). Inibições, sintomas e ansiedade. In Edição Standard Brasileira das Obras Psicológicas Completas de Sigmund Freud. v. XIX. Rio de Janeiro: Imago. (Trabalho original publicado em 1925a).

Freud, S. (1996). A negativa. In Edição Standard Brasileira das Obras Psicológicas Completas de Sigmund Freud. v. XX. Rio de Janeiro: Imago. (Trabalho original publicado em 1925b).

Gorostiza, L. (2006). Tentações da transferência. Asephallus - Revista eletrônica do núcleo sephora. Rio de Janeiro: n. 1, 2006. Recuperado em 15 de junho de 2011, de $<$ http://pt.scribd.com/doc/40716025/As-tentacoes-da-transferencia>.

Guimarães, L. (2012). Te devoro. In H. Caldas et al. (Orgs.). O feminino que acontece no corpo - a prática da psicanálise nos confins do simbólico. Belo Horizonte: Scriptum.

Jorge, M.A.C. (2006). Lacan e a estrutura da formação psicanalítica. In Lacan e a formação do psicanalista. Rio de Janeiro: Contra capa.

Lacan, J. (2001, dez.). O lugar da psicanálise na medicina. Revista Opção Lacaniana, São Paulo, n. 32, p. 14.

Lacan, J. (2002). O seminário. Livro 3. Psicoses. Rio de Janeiro: Jorge Zahar. (Trabalho original publicado em 1955-1956).

Lacan, J. (2008). O seminário. Livro 11. Os quatro conceitos fundamentais da psicanálise. Rio de Janeiro: Jorge Zahar. (Trabalho original publicado em 1964).

Lacan, J. (2008). O seminário. Livro 17. O avesso da psicanálise. Rio de Janeiro: Jorge Zahar. (Trabalho original publicado em 1969-1970).

Lacan, J. (2009). O seminário. Livro 1. Os escritos técnicos de Freud. Rio de Janeiro: Jorge Zahar. (Trabalho original publicado em 1953-1954).

Laurent, D. (2005). Inhibicion, sintoma y angustia, hoy. In El analista mujer. Buenos Aires: Três Haches.

Organização Mundial da Saúde. Classificação Estatística Internacional de Doenças e Problemas Relacionados à Saúde - CID-10. Recuperado em 1 de junho de 2011 de <www.datasus.gov.br/cid10/v2008/cid10.ht...>.

Quinet, A. (2007). As $4+1$ condições da análise. 11ed. Rio de Janeiro: Zahar.

Recalcati, M. (2001, abr.). Os dois nada da anorexia. Correio - Revista da Escola Brasileira de Psicanálise, Brasília, n. 32.

Sauret, M.J. (2006). Psicanálise, psicoterapia, ainda ... . In Alberti, S. \& Figueiredo, A.C. (Orgs.). Psicanálise e saúde mental: uma aposta. Rio de Janeiro: Companhia de Freud.

Silva, A.N. \& Bastos, A. (2006). Anorexia: uma pseudosseparação frente a impasses na alienação e na separação. Psicologia Clínica, Rio de Janeiro, v. 18, n. 1.

Walters, E. (2010, mar.). A americanização da doença mental. Revista Latinoamericana de Psicopatologia Fundamental, São Paulo, v. 13, n. 1, 102-115. 


\section{Resumos}

("Thank God I can throw up, otherwise I'd die": symptoms of bulimia and psychoanalytic clinic at a public hospital)

Manuals of classification and diagnosis are highly objective when describing the etiology, differential diagnosis and treatment for persons suffering from the so-called eating disorders. But whereas medicine as a science must seek generalizations, psychoanalysis has the unconscious as its field of research and the subject as an effect of language. This paper deals with issues based on observations of preliminary interviews in a clinical case where the symptom of bulimia was present. The observations refer to specific aspects of the symptom in psychoanalysis, the radical difference between the concepts of "instinct" and "drive" and the particular production of knowledge in psychoanalysis.

Key words: Psychoanalisys, medicine, symptom, bulimia nervosa

("Heureusement que je vomis, sinon je mourrais": le symptôme boulimique et la clinique psychanalytique dans un hôpital public)

Les manuels de classification et diagnostique font une description bien objective de l'étiologie, du diagnostic différentiel et du traitement destiné aux personnes souffrant des dits troubles de l'alimentation. Toutefois, si la Médecine, comme champ de connaissance scientifique, opère par la généralisation, le domaine de recherche de la Psychanalyse porte sur l'inconscient, sur le sujet comme effet du langage. Ainsi, à partir des observations sur les entretiens préliminaires d'un cas de boulimie, cet article met en relief quelques questions, telles que : les spécificités du symptôme dans la psychanalyse, la différence radicale entre l'instinct et la pulsion, ainsi que la particularité de la production du savoir en psychanalyse.

Mots clés: Psychanalyse, médicine, symptôme, boulimie

("Gracias a Dios vomito, si no moría": el sintoma bulímico y la clinica psicoanalítica)

Los Manuales de clasificación y diagnostico son bastante objetivos y o describen la etiología, el diagnostico diferencial y el tratamiento para todos aquellos que padecen los llamados trastornos alimenticios. Todavía, la medicina como área del saber científico debe generalizar, el psicoanálisis tiene como campo de pesquisa el inconsciente y el sujeto como un efecto del lenguaje. Con esto a partir de observaciones sobre las entrevistas preliminares de un caso en la cual se evidenciaba el síntoma Bulímico, el presente articulo revela algunas reflexiones:las especificaciones de síntomas para el psicoanálisis la diferencia radical entre instinto e pulsión yla particularidad de la producción de saber en psicoanálisis.

Palabras clave: Psicoanálisis, medicina, sintoma, bulimia 


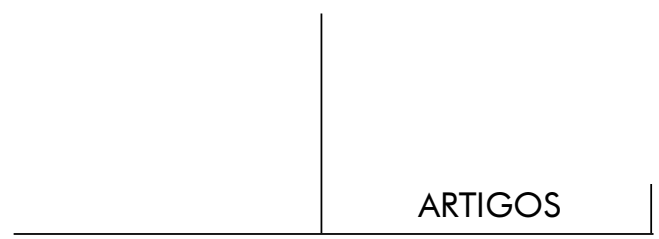

("Gott sei Dank erbreche ich mich, sonst würde ich sterben": das Symptom der Bulimie und die psychoanalytische Klinik in einem öffentlichen Krankenhaus)

Die Klassifizierungs- und Diagnosehandbücher sind objektiv in ihrer Beschreibung der Ätiologie, der differenzierten Diagnose und der Behandlung all derjenigen, die an Essensstörungen leiden. Während die Medizin, als wissenschaftliches Fach, verallgemeinert, hat die Psychoanalyse das Unbewusstsein, das Subjekt als sprachliches Wirkungselement als Untersuchungsgebiet. Ausgehend von Beobachtungen vorangehender Interviews eines Untersuchungsfalls, in dem sich das Symptom von Bulimie klar herauskristallisierte, behandelt der vorliegende Beitrag vorwiegend folgende Punkte: die spezifischen Aspekte des Bulimiesymptoms für die Psychoanalyse, der radikale Unterschied zwischen Instinkt und Trieb und die Eigenheit der Wissensschaffung in der Psychoanalyse.

Schlüsselwörter: Psychoanalyse, Medizin, Symptom, Bulimie

Citação/Citation: Fagundes Netto, M. V. R.; Santos, N. de O.; Benute, G. R. G. \& Lucia, M. C. S. de (2013, set.). "Graças a Deus vomito, senão morria": o sintoma bulímico e a clínica psicanalítica. Revista Latinoamericana de Psicopatologia Fundamental, 16(3), 373-386.

Editor do artigo/Editor: Manoel Tosta Berlinck

Recebido/Received: 17.10.2012/ 10.17.2012 Aceito/Accepted: 19.12.2012 / 12.19.2012

Copyright: () 2009 Associação Universitária de Pesquisa em Psicopatologia Fundamental/ University Association for Research in Fundamental Psychopathology. Este é um artigo de livre acesso, que permite uso irrestrito, distribuição e reprodução em qualquer meio, desde que os autores e a fonte sejam citados / This is an open-access article, which permits unrestricted use, distribution, and reproduction in any medium, provided the original authors and source are credited.

Financiamento/Funding: Os autores declaram não ter sido financiados ou apoiados / The authors have no support or funding to report.

Conflito de interesses/Conflict of interest: Os autores declaram que não há conflito de interesses / The authors declare that has no conflict of interest. 


\section{Marcus Vinícius Rezende Fagundes Netto}

Psicanalista; Professor e supervisor clínico em psicanálise da Universidade Braz Cubas (Mogi das Cruzes, SP, Br); Mestrando em Pesquisa e Clínica em Psicanálise pela Universidade do Estado do Rio de Janeiro - UERJ (Rio de Janeiro, RJ, Br); Pesquisador colaborador da Divisão de Psicologia do Instituto Central do Hospital das Clínicas - FMUSP. (São Paulo, SP, Br).

Rua Epitácio Pessoa 162/87 - República

01220-030 São Paulo, SP, Br

Fone: (11) 8251-0814

e-mail: vinicius.netto@uol.com.br

\section{Niraldo de Oliveira Santos}

Psicanalista; Diretor de Serviço de Assistência da Divisão de Psicologia do Instituto Central do Hospital das Clínicas - FMUSP (São Paulo, SP, Br); Doutorando em Ciências pelo Departamento de Neurologia da Faculdade de Medicina da Universidade de São Paulo (São Paulo, SP, Br); Diretor de Ensino da Clínica Lacaniana de Atendimento e Pesquisas em Psicanálise de São Paulo - CLIPP (São Paulo, SP, Br).

Rua Veríssimo Glória, 149 - Sumaré

01251-140 São Paulo, SP, Br

Fone: (11) 3088-8409

Fone: (11) 9315-5630

e-mail: niraldo@usp.br

\section{Glaucia Rosana Guerra Benute}

Diretora do Serviço de Pesquisa da Divisão de Psicologia do Instituto Central do Hospital das Clínicas - FMUSP (São Paulo, SP, Br); Doutora em Ciências pelo Departamento de Obstetrícia e Ginecologia da Faculdade de Medicina da Universidade de São Paulo (São Paulo, SP, Br). Rua Veríssimo Glória, 149 - Sumaré

01251-140 São Paulo, SP, Br

Fone: (11) 3088-8409

e-mail: grguerra@uol.com.br

\section{Mara Cristina Souza de Lucia}

Psicanalista; Diretora da Divisão de Psicologia do Instituto Central do Hospital das Clínicas FMUSP (São Paulo, SP, Br); Doutora em Psicologia pela Pontifícia Universidade Católica de São Paulo - PUC-SP (São Paulo, SP, Br).

Rua Veríssimo Glória, 149 - Sumaré

01251-140 São Paulo, SP, Br

Fone: (11) 3088-8409

e-mail: dipich@hcnet.usp.br 